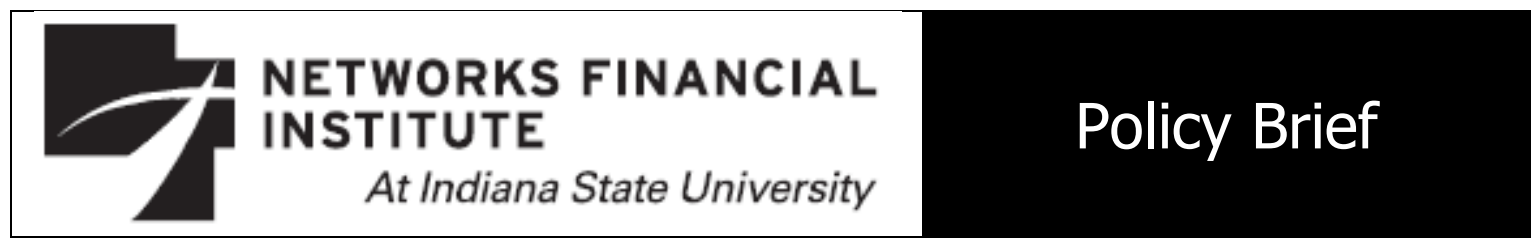

2010-PB-07

September 2010

\title{
Rethinking Consumer Protection Regulation in Insurance Markets
} Sharon Tennyson

Abstract: This paper examines consumer protection regulation in insurance markets and discusses how regulation could be made more efficient and robust. The paper argues that regulatory costs could be lowered and effectiveness enhanced by better targeting regulations to address market failures. Regulations should also recognize and attempt to harness the private incentives of market participants to encourage behaviors that are consistent with regulatory objectives. Applying theoretical and empirical insights from academic research and the experiences of other jurisdictions, specific approaches that make use of these principles are discussed.

About the Author: Sharon Tennyson is Associate Professor in the Department of Policy Analysis and Management at Cornell University. Dr. Tennyson is a noted expert on economic and policy issues related to insurance and has published extensively on topics related to government regulation of insurance markets, insurance fraud, insurance distribution and consumer attitudes and knowledge of insurance. Her research has received funding from a variety of sources including the National Science Foundation, and has been published in high quality economics, insurance and finance journals and in prestigious edited collections. Dr. Tennyson is a member of several national organizations and editorial boards and is a past president of the Risk Theory Society. She holds a Ph.D. in economics from Northwestern University and was previously on the faculty of the Wharton School of the University of Pennsylvania.

Keywords: Consumer Protection, Insurance.

\section{JEL Classifications: G22, G28, D18.}

The views expressed are those of the individual author and do not necessarily reflect official positions of Networks Financial Institute. Please address questions regarding content to Sharon Tennyson at sharon.tennyson@cornell.edu. Any errors or omissions are the responsibility of the author. NFI working papers and other publications are available on NFI's website (www.networksfinancialinstitute.org). Click

"Thought Leadership" and then "Publications/Papers." 


\section{Rethinking Consumer Protection Regulation in Insurance Markets Sharon Tennyson}

\section{Introduction}

The global financial crisis has undermined trust in financial institutions and reduced faith that market discipline alone can effectively regulate the behavior of firms. As a result, demands for consumer protections have increased and strengthening consumer protection regulation has become a cornerstone of financial regulatory reform. Both the federal and state governments have enacted significant new protections since the crisis. This renewed public and political interest in consumer protections and the heightened interest in reshaping the regulatory landscape provide a timely opportunity to rethink consumer protection regulation in insurance markets.

Consumer protections seek to keep in check insurers' interactions with their customers, and the reach of consumer protection regulation is broad. ${ }^{1}$ Regulators oversee the entry of firms and agents into the market and the content of insurance policy forms. Advertising and marketing, pricing and underwriting, policy cancellation and nonrenewal, and the settlement of claims are also monitored. ${ }^{2}$ Regulator actions take on several dimensions including promoting market transparency, restricting specific behaviors, and enforcing compliance with rules.

Criticisms of state insurance regulation are numerous but often focus on the reach and form of consumer protections. Critiques include a lack of coordination across the states, excessive regulatory cost burdens, and anti-competitive effects (Harrington, 2006). The

\footnotetext{
${ }^{1}$ The actions of state regulators make up only one part of the regulatory apparatus policing insurer market conduct. State and federal legislatures may also make rules for the industry by passing new legislation. Additional protections are afforded to insurance consumers through the courts.

${ }^{2}$ Unlike in the banking industry where prudential regulation is employed primarily to reduce bank runs that may lead to banking and financial crises, systemic risk is not an important concern in insurance markets (Grace, 2010; Weiss, 2010). Because of this, one can argue that solvency regulations and insurance guarantee funds should be categorized as consumer protection regulations (Schwarcz, 2010). This policy brief focuses only on those areas that more traditionally fall under market conduct regulation.
} 
regulatory process of market conduct supervision has been a particular target of criticism (U.S. Government Accounting Office, 2003; Klein and Schact, 2001).

State regulators and the National Association of Insurance Commissioners (NAIC) have been working for years to improve insurance market regulation. In 2003, the NAIC adopted an Insurance Regulatory Modernization Action Plan that established market analysis, market conduct and interstate collaboration as the three pillars of market regulation (NAIC, 2009). Nonetheless, change has proved time-consuming and the states are still working to define many specific regulatory practices. Coordination difficulties arise in part due to questions surrounding the role of the NAIC, which is a voluntary organization of state insurance commissioners and has no regulatory authority. As a result, many observers question the ability of state-centered regulation to achieve needed reforms.

Leaving aside the question of whether the states or federal government should undertake insurance regulation, this paper identifies and discusses important principles that should be considered when designing consumer protection regulations in these markets. The paper proceeds by first describing the major forms of consumer protection regulation in insurance markets. Regulations are then evaluated in light of the economic rationale for consumer protections in insurance markets. Issues and challenges in regulatory design are identified, and alternative approaches are discussed.

\section{Consumer Protection Regulations}

For insurance, as for most other financial products, disclosure regulations are common. Like firms in other industries, insurers are also subject to states' unfair trade practices laws and thus to general prohibitions on unfair or deceptive behaviors. However, compared to regulators of other financial services, state insurance regulators rely more 
heavily on direct restrictions on products, prices and the actions of sellers (Bair, 2003). These restrictions are among the more contentious elements of consumer protection regulation.

Many states place restrictions on insurance prices and on insurers' use of specific consumer characteristics to determine insurance eligibility and pricing (underwriting restrictions). The aim of most price regulation is to reduce the cost of insurance to high-risk consumers. Regulatory restrictions on pricing take the form of limits on rate changes, restrictions on rates for high-risk consumers, prohibitions on the use of certain rating factors, and rules that require insurers to offer coverage to most consumers. This form of regulation does not occur in every state and is most common in select property-liability insurance markets such as automobile, homeowners, and workers compensation insurance, and in the markets for individual and small group health insurance.

Policy forms and contractual language for most consumer-oriented insurance products are subject to regulatory prior approval in most states. To attempt to reduce regulatory costs and delays associated with product approval at the state level, the NAIC has promoted coordinated approval actions among the states. This has been only partially successful, however. ${ }^{3}$ Regulatory prior approval of products may also be used to impose restrictions on product features. Restrictions may include mandated insurance coverage provisions and prohibition of certain forms of coverage. In some cases, regulations or legislation mandate that all insurers provide standardized coverage.

An important aspect of consumer protection regulation is determining whether insurers are complying with regulatory requirements, and uncovering insurer practices or actions that regulators view as unfair or unreasonable (Klein and Schacht, 2001). Monitoring is achieved through market analysis and through market conduct examinations of individual

\footnotetext{
${ }^{3}$ As of 200936 states participate in an interstate compact for life and annuity products (IIPRC, 2009). There is no property-casualty version of the interstate compact.
} 
insurers. Market analysis includes the use of data on industry trends, regulatory data submitted by firms, consumer complaints, and other information. Market conduct examinations are conducted on-site at the insurers' premises and encompass a review of policy and claim files and other internal databases to evaluate marketing and sales practices, underwriting decisions, pricing, and claims settlements. Specific areas of examination include determination that the actions of the insurer are consistent with advertising materials, that policies sold and rates charged are consistent with state rules, and that claims are paid within a reasonable period of time (Klein and Schacht, 2001).

States also provide Internet and telephone complaint services to consumers and track complaints filed against each insurer. Each state reports complaints to a centralized database maintained by the NAIC, providing a means of comparative and coordinated complaint monitoring. Information obtained from consumer complaints may be used to trigger additional regulatory monitoring, including on-site market conduct examinations. Consumer complaints may also be a source of regulatory action, leading to disciplinary actions or fines. These cases are relatively rare, however, and represent only about one percent of complaints in a typical year (NAIC, 2010a).

Regulators who determine that an insurer is not in compliance with state laws and regulations have a variety of enforcement tools at their disposal. Regulators may impose fines or penalties as a result of errors found in market conduct examinations. Regulators may also require an insurer to remedy deficiencies found in an examination or through other means and have the authority to pursue civil and criminal actions in the courts. Licensing authority provides another avenue for enforcement. All insurers and producers (agents) operating in a state must be licensed by the state insurance department. Although licensing is 
generally viewed as a requirement for entry, license withdrawal may be used as an enforcement tool. ${ }^{4}$

\section{Rationales for Consumer Protection Regulation}

In the absence of market imperfections, unfettered competition will lead to the largest possible gains from trades, and thus to the maximum achievable societal benefits. This result is the standard economic efficiency argument for leaving markets to operate free from government regulations. The economic case for regulation must therefore be made based on the existence of conditions that prevent a market from achieving this efficient outcome.

The primary motivation for consumer protection regulation in insurance is the idea that consumers in these markets are imperfectly informed about product characteristics. The quality characteristics of an insurance policy include the strength of both the insurer's ability and willingness to pay losses and the breadth of loss events covered under the policy in relation to the potential size and scope of losses (Iuppa, 2006). These quality characteristics are difficult to know with certainty due to the complexity of contractual language and restrictions, the contingent nature of the claim payment services provided, and the fact that the services are provided in the future.

Price comparisons may also be difficult because prices depend on specific elements of coverage and on consumer risk characteristics. Coverage features include such details as investment strategies and calculation of returns, the definition of insured events, or the amounts of coverage extended for specific events. Prices depend upon individual risk characteristics, which may include previous loss experience, demographics, financial history,

\footnotetext{
${ }^{4}$ Removal of license is relatively rare. In 2006, for example, 77 company certificates of authority and 1509 agent licenses were revoked. These represent 0.1 percent of all companies and 4.4 percent of all agents holding licenses in 2006 (NAIC, 2006).
} 
or lifestyle choices (Iuppa 2006). The wide variations in products and prices create difficulties in learning about price and quality and lead to information asymmetries in which consumers have an information disadvantage. Information asymmetries give rise to the potential for insurer misrepresentation or manipulation.

While consumer information disadvantages are not unique to insurance markets, cognitive limitations and psychological biases in consumers' risk decisions suggest that they may be more persistent and more consequential in these markets. ${ }^{5}$ In complex decision tasks, individuals may make decision errors due to cognitive processing costs or the use of mental shortcuts. Much evidence also suggests that consumers do not have a good feel for probabilities, do not treat losses and gains symmetrically, and tend to overestimate emotionally-laden loss events while underestimating low-probability loss events. In the insurance context, these tendencies may lead to poor choice of contracts due to a failure to appropriately understand and value various aspects of insurance benefits (Kirsch, 2002).

A related concern is that insurers, recognizing consumers' limitations, may design products or disclosures in ways that take advantage of them (Hansen and Kysar, 1999). For example, insurers who recognize consumers' cognitive biases could manipulate disclosures regarding returns to make their products appear more desirable. Moreover, risk disclosures or other cautions may not be adequately heeded by consumers if products are otherwise marketed as “safe." Sales agents' representations or recommendations may also have the effect of downplaying written disclosures due to consumers' cognitive biases (Kirsch, 2002).

These market and consumer characteristics reduce the incentives of insurers to compete over price and quality and raise the potential for insurers to misrepresent products or product quality to induce consumer purchases. Consumers may make decisions that are

\footnotetext{
${ }^{5}$ See the discussions in Camerer, et. al, 2003; Thaler and Sunstein, 2008; Barr et. al, 2008.
} 
not in their own interest, reducing the gains from transactions undertaken in the market. More importantly, consumers' recognition of their information and decision-making disadvantages may undermine confidence in the market, reducing their willingness to engage in transactions. These effects will reduce the benefits from insurance, creating efficiency losses.

On the other hand, firms have incentives to maintain faith in their products in order to maintain consumer demand. If consumers cannot determine with certainty the quality of a product and lack confidence in a firm's honesty about quality, consumer willingness to purchase will be greatly reduced. However, if poor quality is difficult for consumers to determine, a firm will experience no (immediate) reputation loss from misrepresentations. Under these conditions, market discipline may not provide sufficiently large or timely penalties to prevent such behaviors.

Put another way, the problem is that industry reputation is a public good which benefits all firms by increasing consumer confidence and insurance demand. Collectively, the insurance industry has an interest in promoting consumer confidence. However, a single firm or individual seller may have a financial incentive to free ride on that reputation through lower standards of conduct that lead to higher short term payoffs. Consumers' difficulty in observing quality reinforces the problem by making it difficult for other sellers to signal their high quality or standards. Legal remedies or regulatory restrictions may be needed to assure that consumers are treated fairly by insurers.

\section{Rethinking Consumer Protection Regulation}

Existence of market imperfections is not sufficient to justify government intervention. Because government regulation is both costly and imperfect, we must consider whether government has the capability to produce an outcome that is closer to the social 
optimum. The key difficulty in designing consumer protection regulations is in achieving the appropriate balance of costs and benefits. Restrictions on market behavior create efficiency costs but produce greater protections from adverse outcomes for some consumer groups. Fewer restrictions lead to lower efficiency costs but to higher information and monitoring costs for consumers and regulators (Trebilcock, 2003).

Recognition of these trade-offs has recently motivated interest in moving toward more targeted and limited use of direct regulations, and toward regulations which attempt to harness the private incentives of market participants to encourage behaviors that are consistent with regulatory objectives. Using these perspectives and based on insights from academic research and on the experiences of other jurisdictions, this section considers challenges and solutions in regulatory design of consumer protection regulation in U.S. insurance markets.

\section{Price Regulation}

One important target for regulatory reform is price regulation. If markets are competitive, price regulation results in efficiency losses by reducing insurers' incentives to participate in the market. Price regulation in property-liability insurance has been particularly contentious. ${ }^{6}$ Many studies have documented substantial market distortions in states where rate regulation is stringently applied, including exit of insurance providers, reduced insurance availability and rising claims costs. ${ }^{7}$

\footnotetext{
${ }^{6}$ Property-liability insurance markets in the U.S. are generally thought to be competitive. Health insurance may be an exception due to high concentration of insurers in local markets: see Dafny (2008) and Dafny, Duggan and Ramanarayanan (2009). Thus, price regulation in health insurance may have different effects than in other lines of insurance.

${ }^{7}$ See the discussions in Harrington (1992), Cummins (2002) and Tennyson (2007).
} 
Price regulation as practiced in many insurance markets - regulating prices to provide subsidies to high-risk groups - distorts consumers' incentives as well. ${ }^{8}$ Price subsidies to promote insurance access may not just affect decisions about insurance purchase but may also distort decisions to engage in insured activities. This is particularly a problem in markets for automobile and homeowners insurance. For example, regulatory price subsidies encourage driving by high-risk youth without regard to the accident risks created; regulatory subsidies similarly promote driving in high-density urban areas while not accounting for pollution and congestion costs. Subsidized property insurance in hurricaneprone areas encourages building on beaches and leads to environmental degradation. Even ignoring the external costs to society, insurance price subsidies may lead to greater risktaking and thus to higher costs in the long run (Weiss, Tennyson and Regan, 2010).

Regulatory schemes that promote greater risk-awareness and incentives to reduce accident costs would be far more preferable. Specific examples include bonus-malus schemes that raise (future) premiums for drivers with automobile accidents and reduce premiums for drivers with clean records. We observe some insurers privately offering these pricing schemes, but regulators may improve access while providing beneficial safety incentives where schemes can be publicly enforced. ${ }^{9}$ In property insurance markets, price incentives for mitigation and enforcement of strict building codes would provide better incentives for risk reduction and in the long run would enhance insurance availability. Offering a wide choice of insurance benefits at different price points is another approach to enhancing access. Allowing consumers to choose limited tort automobile insurance has been

\footnotetext{
${ }^{8}$ In practice, residual market pools to provide a small fraction of consumers with modest price subsidies do not appear to distort markets and incentives by much. In the interest of social fairness (rather than price equity, which is best served by risk-based pricing), minimal intervention in the pricing mechanism to provide for residual markets probably does not cause much lost efficiency.

${ }^{9}$ Some other countries have imposed such rules and empirical studies show that driver behavior is sensitive to these price signals (Dionne and Ghali, 2005).
} 
successful in some states. Pay-as-you-drive insurance is another contract choice that can lower prices for some drivers.

\section{Product Restrictions}

Another area for reform is what is often seen as the heavy-handed use of insurance product restrictions. Economic theory emphasizes information disclosure as the solution to problems of consumer information. In practice, however, product regulation may lead to better outcomes if consumers may have difficulty making effective use of disclosures. Relying solely on disclosures may be particularly difficult in insurance markets because the characteristics of products (services) vary across consumers and over time (Trebilcock, 2003). Standardization may facilitate consumer comparison shopping and simplify the information consumers require when choosing an insurance policy (Grace and Scott, 2009).

Insurance product regulation is intended to foster market transparency by assuring that contracts are clear and do not contain hidden clauses that may be used to mislead consumers (Grace and Scott, 2009). However, product regulation causes excessive standardization and will reduce product innovations that may benefit consumers. Detailed product restrictions coupled with product approval at the state level also introduce significant regulatory costs and delays. Coordinating the approval process across the states represents a step toward greater efficiencies but continues the existing philosophy of exhaustive regulatory review of individual coverage features.

Regulators might consider restricting the focus of product approvals to "broad" coverage or other "plain vanilla" coverage and require that such policies be offered as a choice to all consumers (Barr et. al, 2008; Bar-Gill and Warren, 2008). Insurers would be allowed to offer additional policies with different features, subject to clear disclosure statements, without seeking specific prior approval from regulators. This approach would 
preserve the availability of a range of coverage features while increasing the transparency of contracts and preserving some of the benefits of standardization.

Ideal regulations would increase insurers' private incentives to offer coverage that is fair and transparent. Legal standards enforced by the courts already incorporate high standards of clarity and transparency in insurance contracts. This may be sufficient in markets in which at least some consumers are well informed and have resources to engage the legal system. In other markets, strong regulatory penalties for coverage features that are determined to be misleading, unclear or unfair would provide insurers with strong incentives to create simpler and more transparent contracts, while allowing product innovation and consumer choice. They would also encourage insurers to write clear disclosures and to simplify policy language to ensure consumers' understanding of their products.

\section{$\underline{\text { Disclosure Regulation }}$}

Increasing consumers understanding and use of disclosures would make it easier to eliminate restrictive product and rate regulations. Currently, research suggests that many consumers do not understand insurance disclosures and most consumers do not read them (Cude, 2005). Recent surveys also suggest that consumers have a poor understanding of policy language and terms. For example, the NAIC found that many consumers do not know what a pre-existing condition is in their health insurance policy, and a vast majority of consumers do not understand what a liability coverage amount of 100/300/100 represents in their automobile insurance policy (NAIC, 2010b).

There is a large literature in marketing, psychology and economics on consumers' use and understanding of labels and warning statements which could be used to guide the design of insurance disclosures. This research literature suggests that virtually all features of disclosures - content, form, size, placement and specific language - affect consumers' 
recollection, understanding and interpretation. Several fundamental points include prominent display, simple language, and the use of attention devises such as boxes or declarative statements (e.g., "Warning" or "Attention"). Some research also suggests that requiring consumers to sign that they have read the disclosure leads to greater attention.

Some research specific to insurance disclosures has already been undertaken. The American Council of Life Insurers (ACLI) sponsored a research effort of this kind in 2006, developing two-page disclosures for annuities products and using focus groups with both consumers and financial advisors to evaluate their effectiveness. Features of disclosures that consumers identified as positive include shortness of length, use of examples, use of bullet point format, use of underlining and short sentences, and language that avoids jargon or technical terms (Greenwald, 2007). Similar research has been undertaken by Consumers Union $(\mathrm{CU})$ in the health insurance context. ${ }^{10}$ Based on consumer focus groups, CU found that consumers need assistance in shopping for health insurance and that a standardized "plan summary" included with the rate quote is a useful disclosure mechanism (Wroblewski, 2007).

Another avenue for improving consumers' decisions is to promote better understanding of insurance. Recognizing this, insurance regulators provide consumers with a wealth of information through online and printed sources. This includes both general information about the nature of insurance and specific insurance policies, and comparative information about insurance company prices and consumer satisfaction. Consumer hotlines in each state also field thousands of inquiries each year from consumers who have questions about their insurance. Yet, as noted above, research reveals that consumers generally have a poor understanding of insurance. Results of the NAIC's surveys of consumer knowledge

\footnotetext{
${ }^{10}$ The Federal Trade Commission (FTC) has used consumer research to identify improvements to mortgage disclosures and credit card disclosures.
} 
may provide helpful information to insurers and regulators regarding terminology that should be changed or insurance concepts that should be specifically explained to consumers. Market Conduct Supervision

State market conduct examinations have been a focus for improvement in the past decade. The NAIC has developed the Market Regulation Handbook intended to promote a standard set of practices and efficient use of resources across the states (NAIC, 2009). As part of this coordination, states are developing a uniform market analysis process to review complaint activity, regulatory actions, changes in premium volume, and other key market indicators (Iuppa, 2006). Coordination is intended to provide regulators with collaborative analysis and regulatory interventions, and to provide recommendations regarding corrective actions and common solutions.

States increasingly make use of risk-based approaches to market conduct exams, targeting insurers for examination based on consumer complaints or market analysis. This approach is important, and market analysis systems should be designed specifically to provide regulators with an "early warning system" of potential problems. Risk factors should be based on the potential for hidden risks or on the potential for consumers to fail to appreciate problems due to cognitive or psychological decision factors (Trebilcock, 2003).

The difficulty is in determining what constitutes an appropriate targeting mechanism. A standardized mechanism for assessing insurer conduct would be useful. In this spirit, in recent years states have begun to impose requirements for insurers to submit a market conduct annual statement, providing summary data on company functions such as claim denials and delays, policy cancellations and litigated claims (NAIC, 2009). ${ }^{11}$ Some insurers have suggested requirement of the statement should be determined on a risk-basis and/or

\footnotetext{
${ }^{11}$ Currently 29 states require this statement from at least some insurers.
} 
that small insurers should be exempt. On the contrary, a statement of this kind should be required of all insurers and used as an input to risk-based supervisory decisions.

In addition, making market conduct statistics available to the public may provide insurers with incentives to monitor and improve internal standards. Because consumers may not read or understand annual statement data, information could be published in the form of a letter rating much like financial ratings and could appear on all product offerings. ${ }^{12}$ The idea is that public information will put competitive pressure on insurers with poor records. For example, public posting of restaurant health ratings has been shown to significantly decrease hospitalizations for food-borne illness, increase levels of restaurant sanitation and shift revenue toward restaurants that receive higher grades and away from restaurants that receive lower grades (Jin and Leslie, 2003; Simon et al., 2005). Public disclosure of insurers' market conduct grades could harness these same forces to improve consumer protection in insurance markets.

\section{Consumer Dispute Resolution}

State insurance departments receive a large number of contacts from consumers each year. Collectively, the states receive nearly 200,000 confirmed consumer complaints annually and many multiples of this number in consumer inquiries (NAIC, 2010a). The most common consumer complaints involve claims settlements: complaints about claim denials, delays, or payment amounts account for 50 percent of complaints in a typical year.

However, insurance departments have no authority to require an insurer to settle a claim and rely on conciliation, mediation and explanation in their dispute resolution (Schwarcz, 2009). Indeed, the most frequent outcome of a complaint is provision of information or advice to

\footnotetext{
${ }^{12}$ The letter rating could be determined from the market conduct data alone or in combination with other regulatory inputs.
} 
the consumer (NAIC, 2010a). Other mediation mechanisms include private arbitration and lawsuits.

In many other countries, a financial services or insurance ombudsman office (usually separate from the regulator) is empowered to adjudicate consumer disputes with insurance companies (Canadian Council of Insurance Regulators, 2004). A key difference between the role of an insurance ombudsman and that of U.S. regulators in mediating disputes is that the ombudsman is legally empowered to bind insurers to pay consumers.

Ideally, ombudsman review should be reached only after other adjudication efforts fail to voluntarily settle a complaint, and most complaints should be voluntarily settled. In the U.K., the Financial Ombudsman Service (FOS) operates on this model. Adjudicators have access to the insurers' internal files on each complaint, access to previous ombudsman decisions to use as guidelines in resolving a complaint, and insurers must pay a fee for each complaint handled by the FOS. Schwarcz (2009) argues that these features support attainment of voluntary settlements. This model may be preferred to the current mix of resolution mechanisms used in the U.S. Benefits include expected reductions in the cost and uncertainty associated with dispute resolution, and enhanced incentives for insurers to improve internal systems and standards for resolving consumer disputes. Increased transparency of outcomes may also lead to a more informed consuming public.

\section{Conclusion}

Several features of insurance markets and consumer decisions raise questions about whether an unfettered market will produce the efficient outcomes typically associated with perfect competition. These include complex contingent contracts, persistent information asymmetries, and consumer decision psychology. These create a case for regulatory oversight to protect consumers and to enhance market performance. This paper has argued that 
regulatory costs could be lowered and effectiveness enhanced by better targeting regulations to address market failures. Regulations should also recognize and attempt to harness the private incentives of market participants to encourage behaviors that are consistent with regulatory objectives.

The paper has discussed specific approaches to insurance regulation which make use of these principles. Examples include "risk-based" supervision in which firms are targeted for more active oversight based on indicators of the relative need for oversight, and regulations that create incentives for firms to improve and monitor their own internal standards of behavior. These perspectives are beginning to be employed in insurance market regulation, and these developments should be expanded and encouraged. 


\section{Bibliography}

Bair, Sheila. 2004. Consumer Ramifications of an Optional Federal Charter for Life Insurance.

Isenberg School of Management, University of Massachusetts.

http://www.isenberg.umass.edu/finopmgt/uploads/textWidget/2494.00004/docum ents/bair-cons-ramifications.pdf.

Barr, Michael S., Sendal Mullainathan and E. Shafir. 2008. Behaviorally Informed Financial Services Regulation. New American Foundation Working Paper, October. http://www.newamerica.net/files/naf behavioral v5.pdf.

Bar-Gill, Oren and Elizabeth Warren. 2008. Making Credit Safer. University of Pennsylvania Law Review 157(1): 1-101.

Bartlett, Dwight K. III, Robert W. Klein and David T. Russell. 1999. Attempts to Socialize Costs in Voluntary Insurance Markets: The Historical Record. Journal of Insurance Regulation 17: 478-511.

Camerer, Colin et al. 2003. Regulation for Conservatives: Behavioral Economics and the Case for Asymmetric Paternalism. University of Pennsylvania Law Review 151(3): 1211 1254.

Canadian Council of Insurance Regulators. 2004. Risk-Based Market Conduct Regulation: A Survey of Approaches. http://www.ccir-ccrra.org/en/init/RbMC/Survey$\underline{\text { Risk Based Supervisory Approaches.pdf. }}$

Cude, Brenda. 2005. Insurance Disclosures: An Effective Mechanism to Increase Consumers' Market Power? Journal of Insurance Regulation 24(2): 57-80.

Cude, Brenda. 2007. Insurance Disclosures: Implications for Insurance Regulators of Recent Research. Journal of Insurance Regulation 26(2): 3-5. 
Cummins, J. David. 2002. (Ed.) Deregulating Property Liability Insurance Markets. Washington, D.C.: AEI-Brookings Joint Center for Regulatory Studies. http://regmarkets.org/admin/authorpdfs/redirect-safely.php?fname $=. . /$ pdffiles $/$ cummins.pdf.

Dafny, Leemore S. 2008. Are Health Insurance Markets Competitive? NBER Working Paper No. 14572.

Dafny, Leemore S., Mark Duggan and Subramaniam Ramanarayanan. 2009. Paying a Premium on Your Premium? Consolidation in the Health Insurance Industry. NBER Working Paper No. 15434.

Dionne, G., and O. Ghali. 2005. The (1992) Bonus-Malus System in Tunisia: An Empirical Evaluation. Journal of Risk and Insurance 72(4): 609-633.

Grace, Martin F. 2010. The Insurance Industry and Systemic Risk: Evidence and Discussion. Networks Financial Institute Policy Brief 2010-PB-02. http://www.networksfinancialinstitute.org/Lists/Publication\%20Library/Attachme nts/160/2010-PB-02 Grace.pdf.

Grace, Martin F. and Hal Scott. 2009. An Optional Federal Charter for Insurance: Rationale and Design, in Grace, M.F. and R.W. Klein, eds. 2009. The Future of Insurance Regulation in the United States. Washington: Brookings Institution Press.

Greenwald, Matthew. 2007. Using Research to Help Make Disclosure Statements More Effective: A Case Study in Research Design and Implementation. Journal of Insurance Regulation 26(2): 11-20.

Hansen, Jon D. and Douglas A. Kyser. 1999. Taking Behavioralism Seriously: The Problem of Market Manipulation. New York University Law Review 74: 630-749.

Harrington, Scott E. 1992. Rate Suppression. Journal of Risk and Insurance 59: 185-202. 
Harrington, Scott. E. 2006. Federal Chartering of Insurance Companies: Options and Alternatives for Transforming Insurance Regulation. Networks Financial Institute Policy Brief 2006-PB-02.

http://www.networksfinancialinstitute.org/Lists/Publication\%20Library/Attachme nts/36/2006-pb-02 Harrington.pdf.

Interstate Insurance Product Regulation Commission (IIPRC). 2009. Annual Report. Online at http://www.insurancecompact.org/

Iuppa, A. 2006. Insurance Regulatory Reform. Testimony before the U.S. Senate Committee on Banking, Housing and Urban Affairs July 11. http://www.naic.org/Releases/2006 docs/iuppa senate banking testimony.pdf.

Jin, Ginger and Phillip Leslie. 2003. The Effects of Information on Product Quality: Evidence from Restaurant Hygiene Grade Cards. Quarterly Journal of Economics 118: 409-451.

Kirsch, Larry. 2002. Do Product Disclosures Inform and Safeguard Insurance Policyholders? Journal of Insurance Regulation 20(3): 271-295.

Klein, Robert W. and James W. Schacht. 2001. An Assessment of Insurance Market Conduct Surveillance. Journal of Insurance Regulation 20(1): 51-93.

Korobkin, Russell B. and Thomas S. Ulen. 2000. Law and Behavioral Science: Removing the Rationality Assumption from Law and Economics. California Law Review 88(4): 10531146.

National Association of Insurance Commissioners. 2006. Insurance Department Resources Report. Kansas City: NAIC. 
National Association of Insurance Commissioners. 2009. Market Regulation Reforms: An NAIC Issues Brief. Kansas City: NAIC. http://www.naic.org/documents/topics market reg reform brief.pdf.

National Association of Insurance Commissioners. 2010a. Aggregate Consumer Complaints Report. Online at https://eapps.naic.org/cis/

National Association of Insurance Commissioners. 2010b. New NAIC Insurance IQ Study Reveals Americans Lacking in Confidence, Knowledge of Insurance Choices. Press Release, April 6. Online at http://www.naic.org/Releases/2010 docs/iiq_new.htm.

Schlesinger, Harris and J.-Matthias Graf von der Schulenberg. 1993. Consumer Information and Decisions to Switch Insurers. The Journal of Risk and Insurance 60(4): 591-615

Schwarcz, Daniel. 2009. Redesigning Consumer Dispute Resolution: A Case Study of the British and American Approaches to Insurance Claims Conflict. Tulane Law Review 83: $735-812$.

Schwarcz, Daniel. 2010. Regulating Insurance Sales or Selling Insurance Regulation? Against Regulatory Competition in Insurance. Minnesota Law Review 94(6): 1707-1788.

Simon, Paul et al. 2005. Impact of Restaurant Hygiene Grade Cards on Foodborne Disease Hospitalizations in Los Angeles County. Journal of Environmental Health 67: 32-36. Tennyson, Sharon. 2007. Efficiency Consequences of Rate Regulation in the Insurance Industry. Networks Financial Institute Policy Brief 2007-PB-03. http://www.networksfinancialinstitute.org/Lists/Publication\%20Library/Attachme nts/15/2007-PB-03 Tennyson.pdf.

Tennyson, Sharon, Mary A. Weiss, and Laureen Regan. 2002. Automobile Insurance Regulation: The Massachusetts Experience, in J. D. Cummins, ed. Deregulating Property-Liability Insurance. (Washington, D.C.: Brookings Institution Press), 25-80. 
Thaler, Richard and Cass R. Sunstein. 2008. Nudge: Improving Decisions about Health, Wealth and Happiness. London: Penguin Books.

Trebilcock, Michael J. 2003. Rethinking Consumer Protection Policy, in C.E.F. Rickett and T.G.W. Telfer, eds. International Perspectives on Consumers' Access to Justice. Cambridge: Cambridge University Press.

U.S. General Accounting Office. 2003. Insurance Regulation: Common Standards and Improved Coordination Needed to Strengthen Market Regulation. http://www.gao.gov/new.items/d03433.pdf.

Weiss, Mary A. 2010. Systemic Risk and the U.S. Insurance Sector. Center for Insurance Policy \& Research, National Association of Insurance Commissioners. http://www.naic.org/documents/cipr weiss systemic risk 100223.pdf.

Weiss, Mary A., Sharon Tennyson and Laureen Regan. 2010. Regulated Premium Subsidies on Insurance Costs: An Empirical Analysis of Automobile Insurance. Journal of Risk and Insurance 77(3): 597-624.

Wroblewski, Michael. 2007. Uniform Health Insurance Information Can Help Consumers Make Informed Purchase Decisions. Journal of Insurance Regulation 26(2): 21-37. 